\title{
Anaemia in pregnancy: Prevalence and possible risk factors in Kakamega County, Kenya
}

\author{
Mulambalah Chrispinus Siteti ${ }^{1, ~ *, ~ S i a m b a ~ D o n a l d ~ N a m a s a k a ~}{ }^{2}$, Ogutu Philip Ariya $^{2}$, \\ Siteti Darwin Injete ${ }^{3}$, Wekesa Antony Wanyonyi ${ }^{4}$

\begin{abstract}
${ }^{1}$ Department of Medical Microbiology \& Parasitology, College of Health Sciences, School of Medicine, Moi University, Eldoret, Kenya
${ }^{2}$ Department of Biological Sciences, Faculty of Science, Masinde Muliro University of Science \& Technology, Kakamega, Kenya

${ }^{3}$ College of Health Sciences, Jomo Kenyatta University of Agriculture \& Technology, Nairobi, Kenya

${ }^{4}$ Department of Biological Sciences, Faculty of Science, Egerton University, Njoro, Kenya
\end{abstract}

\section{Email address:}

csmulambalah@gmail.com (M. C. Siteti),dnsiamba@yahoo.com (S. D. Namasaka),Philip_ogutu@yahoo.co.uk (O. A. Philip), darwinsiteti@yahoo.com (S. D. Injete), antony.wekesa@yahoo.com (W. A. Wanyonyi)

\section{To cite this article:}

Mulambalah Chrispinus Siteti, Siamba Donald Namasaka, Ogutu Philip Ariya, Siteti Darwin Injete, Wekesa Antony Wanyonyi. Anaemia in Pregnancy: Prevalence and Possible Risk Factors in Kakamega County, Kenya. Science Journal of Public Health.

Vol. 2, No. 3, 2014, pp. 216-222. doi: 10.11648/j.sjph.20140203.23

\begin{abstract}
Anaemia in expectant women is a serious world-wide public health problem with adverse pregnancy outcomes. Haematological parameters indicative of pregnancy anaemia need to be investigated to provide basis for prompt management of anaemia in pregnancy. The aim of the study was to determine the prevalence of anaemia in pregnant mothers of various age groups and at different gestation periods visiting antenatal clinic at a county level 5 hospital. The ages of recruited participants ranged from 16 to 40 years with a mean age of $26.8 \pm 4.3$ years. A total of 320 blood samples were collected during the first and subsequent visits to antenatal clinic from January to December 2013. The age, marital, socio-economic status, highest level of education, stages of each pregnancy of each participant were recorded. Haemoglobin estimation was done using a HemoCue ${ }^{\circledR}$ B-Hemoglobin system and positive anaemia cases were classified as mild, moderate, severe and very severe based on the world health organization criteria. The haemoglobin concentrations ranged from $6.5 \mathrm{~g} / \mathrm{dl}-15.5 \mathrm{~g} / \mathrm{dl}$ with a mean of $10.2 \pm 1.3 \mathrm{~g} / \mathrm{dl}$. Data was analysed using the Chi-square test and Odds ratio. Out of all blood samples analyzed, $128(40 \%)$ were anaemic of which $62.5 \%(n=80)$ were mildly anaemic cases whereas $37.5 \%(n=48)$ were moderately anaemic and no severe anaemic cases were detected. Anaemia was more prevalent (33.3\% -60\%) in second and third trimesters of pregnancy. Study results confirm that socio-economic deprivation and lack of basic education are important factors that predispose pregnant women to anaemia. Anaemia levels reported are low but persistent and present a potentially serious public health problem to the mother, foetal growth and delivery outcome and therefore require serious attention. It is recommended that the county government initiates free iron supplementation and enlist services of extension nutritionists in an integrated programme for the prevention and management of pregnancy related anaemia.
\end{abstract}

Keywords: Anaemia, Pregnancy, Prevalence, Public Health

\section{Introduction}

Anaemia is a global public health problem affecting both developing and developed countries with major consequences for human health as well as social and economic development $[1,2]$. It occurs at all stages of life cycle, but is more prevalent in pregnant women and young children and is considered to be among the most important contributing factors to the global burden of disease. Anaemia occurs when the concentration of haemoglobin falls below what is normal for a person's age, gender and environment and is often classified as mild, moderate, severe and very severe. Etiological classification of anaemia identifies 3 major causative groups of anaemia as nutritional, marrow disease and haemolytic disease. Anaemia resulting from iron deficiency is the most prevalent form of anaemia (76\%), followed by folate deficiency 20 percent and combined iron and folate deficiency 20 percent. Hookworm infestation, malaria and HIV infections contribute immensely to severe anaemia 
cases reported among pregnant women. It is evident that several factors may be implicated for the high prevalence of anaemia in the pregnant population.

It is estimated that in developing countries anaemia prevalence rates in pregnant women are commonly in the range of 40 to 60 percent. Around half of those with anaemia, suffer from iron deficiency anaemia, while folate deficiencies and other causes account for the major proportion of the remaining anaemia cases.

During pregnancy, foetal and placental growth and the larger amount of circulating blood in the expectant mother, lead to an increase in the demand for nutrients, especially iron and folic acid. Since majority of women in developing countries start pregnancy with already depleted body stores of these nutrients it translates that their extra requirement is even higher than usual. The implication is that a slight change in haemoglobin levels in pregnant women is likely to result in severe and often fatal consequences if not addressed early.

When anaemia is not adequately monitored and addressed in pregnant women, it can result in severe morbidity, mortality and reduces the resistance to blood loss with the possibility that death may result from the blood loss associated with delivery.

The early stages of anaemia in pregnancy are often symptomless and may remain un- recognized clinically with serious outcomes. As the $\mathrm{Hb}$ concentration decline, oxygen supply to vital organs declines and the expectant mothers complain of general weakness, tiredness and headaches. Usually, pallor of the skin and of the mucous membrane, as well as the nail beds and tongue may not become noticeable until $\mathrm{Hb}$ drops to about $7.0 \mathrm{~g} / \mathrm{dl}$. With a further decline in $\mathrm{Hb}$ concentration to $4.0 \mathrm{~g} / \mathrm{dl}$, most body tissues become starved of oxygen and the effect is most marked on the heart muscles, which may fail leading to heart failure and death. While mild and moderate anaemia may not be a direct cause of maternal death, both do contribute towards death from other causes, particularly post-partum haemorrhage. Anaemic mothers do not tolerate blood loss to the same degree as healthy non-anaemic women. During childbirth the loss of small volume of blood in an anaemic mother can be fatal.

The most dramatic health effects of pregnancy related anaemia have widely been highlighted world-wide. They include the observation that anaemic mothers are poor anaesthetic and operative risks because of low resistance to common infections and poor wound healing; renders the offspring vulnerable to anaemia from infancy; low birth weight [13]; preterm delivery and intrauterine foetal death. Given the consequences of anaemia during pregnancy, this problem urgently needs to be addressed and necessitates for continued monitoring and evaluation of anaemia in this vulnerable group.

It is evident that past reported estimates of anaemia for pregnant women did not account for the prevalence in relation to trimesters of pregnancy especially third trimester when anaemia is most likely to be a serious risk of maternal mortality. Further, the roles of socio-economic and demographic risk factors are not routinely reported in literature. We hypothesized that anaemia prevalence would vary by trimester and age of the pregnant woman. The purpose of assessing anaemia was to inform decisionmakers on the problem and suggest measures to be taken to prevent and control pregnancy related anaemia.

\section{Materials and Methods}

\subsection{Study Area, Design and Subject Selection Criteria}

Kakamega county hospital is a Government institution located in Kakamega town, municipality division within latitude $0.2833^{\circ} \mathrm{N}$ and longitude $34.7500^{\circ} \mathrm{E}$. The hospital serves an estimated population of 2 million in an area approximately $3034 \mathrm{Km}^{2}$ and offers a wide range of medical services including antenatal and obstetric care.

Study participants were randomly selected from pregnant women aged 16-40 years during their first visit to the antenatal clinic between 1- January to 31 December 2013, and who gave consent in person or by guardian to participate in the study. Parasitic, chronic infections and haemoglobinopathies are known to lower blood haemoglobin $(\mathrm{Hb})$ concentrations and those who turned positive for these conditions were excluded and referred for appropriate treatment. Three hundred and twenty (320) women at different trimesters of pregnancy consented to participate in the study and were categorized in age groups and social classes. Their levels of education, marital status and stage of pregnancy were recorded. They were clinically examined and thereafter specimen samples were taken for medical analysis.

\subsection{Sample Specimen Collection and Analysis}

Faecal samples were collected and analysed for presence of intestinal parasitic infections. Blood samples were collected and assayed for presence of acute and chronic infections and haemoglobinopathies. Faecal and blood sample collection and analysis were carried out for those who accepted to participate in the study. Confirmed positive cases of parasitic, chronic infections, haemoglobinopathies and those on haematinics were recorded but excluded from study. Given the multi-factorial nature of anaemia, the rationale was to rule out anaemia associated with these conditions and link with certainty positive pregnancy related anaemia cases to iron deficiency.

\subsection{Anaemia Assessment and Classification}

Haemoglobin $(\mathrm{Hb})$ concentration was used to determine level of anaemia because of its reliability, relatively easy and inexpensive and is the most reliable indicator of anaemia. Further, $\mathrm{Hb}$ concentration is considered the most reliable indicator of anaemia at the population level.

Blood samples were collected in ethylene diaminetetraacetic acid (EDTA) tubes, analysed to determine mean $\mathrm{Hb}$ levels of each sample. Anaemic cases 
were classified as mild, moderate or severe based on haemoglobin threshold used to define anaemia in pregnant women. The haemoglobin estimation was done using a HemoCue $^{\circledR}$ B-Hemoglobin system (HemoCue AB, Ängelholm, Sweden). The HemoCue system consisted of a portable, battery-operated photometer and a supply of treated disposable cuvettes in which blood was collected. The instrument is known to be stable and durable with a sensitivity of $82.4 \%$ and specificity of $94.2 \%$. Anaemia in the study was defined by using the world health organization and classified into mild anaemia $(10-10.9 \mathrm{~g} / \mathrm{dl})$, moderate anaemia $(7.0-9.9 \mathrm{~g} / \mathrm{dl})$ and severe anaemia $(<7.0$ $\mathrm{g} / \mathrm{dl})$. Severe anaemic cases and those that could develop into severe anaemia were referred to the obstetrician/antenatal specialist clinic for further assessment and appropriate management.

\subsection{Categorization of Patients into Social Classes}

Patient data was collected by means of pretested structured questionnaires administered by trained personnel. Information required on the questionnaire included sociodemographic characteristics such as age, occupation and educational status. The collected socio-demographic data was used to group the pregnant women into five social classes (Table 1). The main socio-economic indicators used were education, occupational status and income.

Table 1. Classification of participants into social classes based on level of education.

\begin{tabular}{ll}
\hline Social Class & Class Indicators \\
\hline I (Upper Class) & University education or equivalent. \\
II (Upper class) & $\begin{array}{l}\text { Diploma certificate holders or equivalent } \\
\text { professional training. }\end{array}$ \\
III (Middle class) & $\begin{array}{l}\text { Secondary school certificate, primary school } \\
\text { teachers' certificate holders or its equivalents. }\end{array}$ \\
IV (Lower class) & $\begin{array}{l}\text { Secondary School drop-outs or certificate of } \\
\text { primary education holders. }\end{array}$ \\
V (Lower class) & $\begin{array}{l}\text { Those who could neither read nor write, or were } \\
\text { considered as illiterate. }\end{array}$ \\
\hline
\end{tabular}

\subsection{Data Analysis}

Data from questionnaire responses and haemoglobin estimate levels were recorded, coded and entered into a database using SPSS package for analysis. Mean values of anemia, percentages of positive anemia cases were calculated. Chi-square was calculated to determine any association between anemia and socio-demographic factors and stages of pregnancy (trimesters). Statistical significance was set at $95 \%$ confidence level ( $p$-value of less than or equal to 0.05 ( $p$-value $\leq 0.05)$.

\section{Results}

A total of 320 blood samples from pregnant women were analyzed age range 16 to 40 years (mean age $27.1 \pm 4.2$ years), 128 (38.75\%) were anaemic. The haemoglobin concentration ranged from $7.5 \mathrm{~g} / \mathrm{dl}-15.5 \mathrm{~g} / \mathrm{dl}$ with a mean of $10.2 \pm 1.3 \mathrm{~g} / \mathrm{dl}$.

Out of the anaemic cases, $62.5 \%$ were mildly anaemic whereas $37.5 \%$ were moderately anaemic (Table 2). Anaemia was more prevalent in the reproductive lower age group (16-25 years) than in the upper age groups $(>26$ years) but there was no significant association between age and anaemia $(P$ value $>0.05)$. There were no individual cases of severe anaemia detected however overall age group anaemia prevalence approaching $\geq 40 \%$ was considered in the context of severe anaemia or has potential of developing into severe anaemia in the long run.

Table 2. Anaemia levels and prevalence in relation to age of pregnant women.

\begin{tabular}{ccccc}
\hline $\begin{array}{c}\text { Age } \\
\text { groups } \\
\text { (yrs) }\end{array}$ & $\begin{array}{c}\text { Number } \\
\text { examined } \\
\text { (n) }\end{array}$ & \multicolumn{2}{c}{$\begin{array}{c}\text { Levels of anaemia } \\
\text { Mild Moderate }\end{array}$} & $\begin{array}{c}\text { Prevalence } \\
\text { of anaemia }\end{array}$ \\
\hline $16-20$ & 74 & $20(27 \%)$ & $12(16.1 \%)$ & 43.1 \\
$21-25$ & 80 & $20(25 \%)$ & $15(18.8 \%)$ & 43.3 \\
$26-30$ & 85 & $20(23.5 \%)$ & $12(14.1 \%)$ & 37.6 \\
$31-35$ & 53 & $10(18.9 \%)$ & $9(17 \%)$ & 35.8 \\
$\geq 36$ & 28 & $10(35.7 \%)$ & $0(0 \%)$ & 35.7 \\
TOTAL & 320 & 80 & 48 & \\
\hline
\end{tabular}

The prevalence of anaemia was higher in pregnant women in the second and third trimesters than in trimester one (Table 3). The risk of developing anaemia was significantly higher in second trimester $\left(P=0.0000 ; X^{2}\right.$ $=34.1555)$ and third trimester $\left(P=0.0035 ; X^{2}=8.532\right)$.

Table 3. Levels of anaemia in different trimesters of pregnancy.

\begin{tabular}{llll}
\hline Trimesters & $\begin{array}{l}\text { Number } \\
\text { examined }(\mathbf{N})\end{array}$ & $\begin{array}{l}\text { Positive } \\
\text { anaemia cases }\end{array}$ & $\begin{array}{l}\text { Negative } \\
\text { anaemia cases }\end{array}$ \\
\hline $1^{\text {st }}$ trimester & 60 & $8(13.3 \%)$ & $52(86.7 \%)$ \\
$2^{\text {nd }}$ trimester & 110 & $66(60 \%)$ & $44(40 \%)$ \\
$3^{\text {rd }}$ trimester & 150 & $50(33.3 \%)$ & $100(66.7 \%)$ \\
TOTAL & 320 & 128 & 196 \\
\hline
\end{tabular}

Patients with tertiary and university level of education had significantly lower risk of $\left(P=0.0447 X^{2}=4.03\right)$ of developing pregnancy related anaemia (Table 4$)$. The risk of developing pregnancy related anaemia was equal irrespective of marital status. Pregnancy related anaemia was significantly influenced by socio-economic status of the expectant mothers $\left(P=0.021 ; X^{2}=5.3445\right)$. 
Table 4. Association between anaemia in pregnancy and socio-demographic factors.

\begin{tabular}{|c|c|c|c|c|c|c|}
\hline \multirow[b]{2}{*}{ Variables } & \multicolumn{2}{|c|}{ Anaemic } & \multicolumn{2}{|c|}{ Non-anaemic } & \multirow{2}{*}{$X^{2}$} & \multirow{2}{*}{$P$-value } \\
\hline & $\mathrm{N}=128$ & $(\%)$ & $\mathrm{N}=192$ & $(\%)$ & & \\
\hline \multicolumn{7}{|l|}{ Age (years) } \\
\hline $16-20$ & 32 & $(43.1 \%)$ & 42 & $(21.9 \%)$ & 0.42051 & 0.51668 \\
\hline $21-25$ & 35 & $(43.3 \%)$ & 45 & $(23.4 \%)$ & & \\
\hline $26-30$ & 32 & $(37.6 \%)$ & 53 & $(27.6 \%)$ & & \\
\hline $31-35$ & 19 & $(35.8 \%)$ & 34 & $(17.7 \%)$ & & \\
\hline$\geq 36$ & 10 & $(35.7 \%)$ & 18 & $(9.4 \%)$ & & \\
\hline \multicolumn{7}{|c|}{ Education status } \\
\hline University & 3 & $(2.3 \%)$ & 9 & $(4.7 \%)$ & 4.03 & 0.0447 \\
\hline Tertiary & 20 & $(15.6 \%)$ & 40 & $(20.8 \%)$ & & \\
\hline Secondary & 50 & $(39.1 \%)$ & 55 & $(28.7 \%)$ & & \\
\hline Primary & 40 & $(31.3 \%)$ & 60 & $(31.3 \%)$ & & \\
\hline Non-formal & 15 & $(11.7 \%)$ & 28 & $(14.6 \%)$ & & \\
\hline None & 0 & $(0 \%)$ & 0 & $(0 \%)$ & & \\
\hline \multicolumn{7}{|c|}{ Marital status } \\
\hline Married & 113 & $(88.3 \%)$ & 166 & $(86.5 \%)$ & 0.227 & 0.6337 \\
\hline Single & 15 & $(11.7 \%)$ & 26 & $(15.5 \%)$ & & \\
\hline \multicolumn{7}{|c|}{ Socio-economic class } \\
\hline Class I & 4 & $(3.1 \%)$ & 14 & $(7.3 \%)$ & 5.3445 & 0.021 \\
\hline Class II & 10 & $(7.8 \%)$ & 26 & $(13.5 \%)$ & & \\
\hline Class III & 25 & $(19.5 \%)$ & 37 & $(19.3 \%)$ & & \\
\hline Class IV & 64 & $(50 \%)$ & 75 & $(39.1 \%)$ & & \\
\hline Class V & 25 & $(19.5 \%)$ & 40 & $(20.8 \%)$ & & \\
\hline
\end{tabular}

\section{Discussion}

Globally pregnant women anaemia prevalence ranges from $41.8-43.8 \%$ which translates to approximately $56-59$ million pregnant women. The prevalence rate for anaemia amongst pregnant women in the present study at $40 \%$ was within classification of anaemia as a problem of public health significance at national level. The prevalence was comparable with what was obtained in similar studies of $32.8-48.1 \%$ Nigeria, $34.44 \%$ in Venezuela women and $40.4 \%$ among pregnant women in Nigeria. The study findings are however in contrast to reports from other countries, $66 \%$ in Burkina Faso Meda et al. [21], Tanzania at 95\% ; South Africa at $57.3 \%$. It is suggested that the variations may be attributed to different causes of anaemia and dietary differences, population differences, study design and difference in methodology used in determining haemoglobin levels.

The study findings indicate low anaemia prevalence in amongst pregnant women in their first trimester of pregnancy. This could be attributed partly due to physiological hemodilution mostly observed early in pregnancy. Also, these women were likely to be on haematinics which might have improved their haemoglobin levels hence lack of previous anaemia history. Absence of previous history of anaemia is reported to drastically reduce chances of developing pregnancy related anaemia.

During the gestation period, majority of pregnancy related anaemia cases were recorded in second $(60 \%)$ and third (33.3\%) trimesters of pregnancy. It is suggested that it could be attributed partly to un-planned pregnancies. In many developing countries family planning is rarely practised and many un-planned pregnancies take place while mothers are still breast feeding. This exposes the pregnant mother to extraordinary stress that affects her nutritional status and result in depletion of the micronutrient stores of the mother, to the extent that she becomes anaemic from first trimester in the next pregnancy. The daily requirements for iron as well as folate are greater for a woman in the last two trimesters of pregnancy. This need cannot be met by diet alone, but is derived from at least partly from maternal reserves. When iron reserves are already low, due to malnutrition and or frequent pregnancies, anaemia results and progresses to become severe in the second and third trimesters. A pregnant woman with previous history of anaemia is twice more likely to become anaemic as compared to one without history of anaemia and this has a more severe outcome for both the mother and the child. Declining levels of $\mathrm{Hb}$ concentrations accompanied by the decreasing of serum levels of vitamin $A$, ascorbic acid, folate and $\mathrm{B}_{12}$ and multiple vitamin deficiencies have been associated with anaemia in pregnant mothers in the last trimester.

It was evident that anaemia was significantly associated with socio-economic status of the study subjects. The prevalence of pregnancy related anaemia was higher amongst those with low socio-economic status. It was encountered more frequently in classes III- V, than class II, and lower class I. Similar observation have been reported in related study. It is suggested that women in low socioeconomic classes are likely to be poorly educated and often have financial constraints. Such women are likely to find it difficult to access and afford good health services. They are therefore more likely to suffer the adverse effects of poor/inadequate nutrition, acute/chronic infections and worm infestations associated with anaemia as reported elsewhere.

Furthermore, some cases of maternal anaemia often have 
its origin in a woman's life before pregnancy. It may be initiated during infancy or even before a woman's birth, when essential minerals and vitamins deficiencies are detected. Therefore, expectant women in the low socioeconomic class may have chronic iron deficiency anaemia even before pregnancy that may be aggravated by the demands of the foetus during pregnancy.

The development of anaemia in the present study was found to be significantly associated with educational status and socio-economic status. Similar findings have been reported elsewhere. The level of anaemia ranged from low to moderate with no individual cases of severe anaemia detected. The absence of severe anaemia or its existence as low incidence of severe anaemia in expectant women has been reported in related studies [31, 32]. Globally, over $80 \%$ of pregnant women present with moderate or severe public health problem. Severe pregnancy related anaemia is commonly associated with parasitic infections (malaria, intestinal worms) during pregnancy. It is suggested that the low incidence of severe anaemia in the study subjects could be an indication of positive outcome of the ongoing infectious disease intervention strategies undertaken by county public health department in the study area. An aggressive public health awareness campaign on the importance of proper sanitation and the need to seek appropriate treatment of parasitic infections in pregnancy could explain the low prevalence of anaemia subjects with tertiary and university education. It is expected that the element of schooling makes this category of subjects more receptive to new ideas and contents of public health campaigns and hence more likely to practice positive healthy living and treatment seeking behaviour. In addition, educated pregnant women categorised in the middle socioeconomic class are likely be employed and can afford to enrol for ante-natal care, eat nourishing food and or prevent possible parasitic infections. The opposite is true for the un-educated poor, low socio-economic status living in chronic poverty $[33,34,35]$. The other possible reason for high prevalence of anaemia amongst the un-educated and economically deprived expectant women can be explained in part by the fact that their diets lack adequate amounts of iron, adherence to cultural taboos that often lead to selection of food types for pregnant women. The end results are nutritional deficiencies such as iron and vitamin $\mathrm{B}_{12}$ deficiency. This explains why low level of education and socio-economic status are important risk factors in pregnancy related pregnancy $[29,36,37]$. In a related study in Ethiopia the rate of anaemia was higher among illiterate pregnant mothers and those who did not practice family planning. In Uganda Kiwanuka et al [38] reported 84.4 percent of anaemic mothers and multiparity, poor socioeconomical and educational status were the principal reasons for a high prevalence of anaemia. In contrast, in Tanzania Msolla and Kinabo [22] reported that 95 percent of Tanzania pregnant subjects were anaemic and all had basic knowledge on anaemia but despite these knowledge and awareness, the women were still anaemic.
During the gestation period, majority of anaemia case were recorded in second (60\%) and third (33.3\%) trimesters of pregnancy. A significantly high third trimester anaemia has been reported than those in the second trimester elsewhere. Deficiencies of vitamins have been associated with anaemia in pregnant mothers in the last trimester in Tibet expectant mothers. Also, anaemia in the third trimester has been reported to increase with parity.

Cases of severe anaemia were not detected in the present study. A similar observation has been reported in Bangladesh, with a few severe cases in Nepal and Sri-Lanka. Cyril \& Hyacinth [20] reported 40.4 percent of Nigerian pregnant women were anaemic, the majority of them were mildly anaemic and there was no case of severe anaemia.

Study subjects in the lower age brackets had higher anaemia prevalence. This finding is comparable to related observation. In this study, teenage pregnant women had the highest prevalence of anaemia while mothers aged 35 and 39 had the lowest prevalence. However, the higher the mother's attained level of formal education, the lower the observed prevalence of anaemia. Similar findings were reported in United States and Brazil and have been attributed to iron deficiency in teenage age groups.

\section{Conclusion and Recommendation}

It is concluded that the prevalence of pregnancy-related anaemia was significantly higher in last two trimesters of pregnancy, lower age groups and those with low socioeconomic status and low education levels. Anaemia prevalence in general was persisting moderate type but a potentially serious public health problem that can reach epidemic proportions in this group of patients un-reported.

It is recommended that Kakamega county government should initiate surveillance and monitoring at antenatal clinics; offer free iron supplementation and enlist services of extension nutritionists in an integrated programme for the management of anaemia in pregnant women. Further, it is recommended that a regular review of factors which may contribute to the prevalence of the maternal anaemia be undertaken in future.

\section{References}

[1] Ezzati M, Lopez AD, Rodgers A, Vander Hoorn S, Christopher J L Mu et al., Selected major risk factors and global and regional burden of disease. Lancet. 2002; 360:1347-60.

[2] World Health Organization 2004. The prevalence of anaemia in women; WHO/MCH/MSM/92.2

[3] World Health Organization. The World Health Report 2002: Reducing risks, promoting healthy life. Geneva, World Health Organization, 2002.

[4] WHO, 2001, Iron deficiency anaemia, assessment, prevention, and control: A guide for program managers, Geneva: WHO. 
[5] Sifakis S, Pharmakides G. Anemia in pregnancy. Ann NY Acad Sci. 2000; 900125-36.

[6] Seshadri S. Prevalence of micronutrient deficiency particularly iron, zinc and folate in pregnancy women in South East Asia. Br. J. Nutr. 2001;85(supp 2),S 87-92.

[7] Chenoufi B, Essafi B, Star E, Chelli H, Ben HA, Ben AS, Ben TN, Ben AK, Kastilli R. Screening for carential anaemia in pregnant women: Prospective study. Report of 200 cases. Tunis Med. 2001:79:423-8

[8] Olukoya AA \& Abidoye RO. A study of intestinal parasites in antenatal clinic patients in Lagos- Nigeria. Health and Hygiene 1996;55:66-70.

[9] World Bank, World Health Organization, UNFPA. Preventing the tragedy of maternal deaths. A report of the International Safe Motherhood Conference, Nairobi, Kenya. Geneva: WHO. 1987: 1-16.

[10] Roy S and Chakravorty PS. Maternal and perinatal outcome in severe anaemia. J Obstet Gynecol Indian 1992;42:743-50.

[11] Ezzati M, Lopez AD, Rodgers A, Murray CJL. Comparative quantification of health risks: Global and regional burden of disease attributable to selected major risk factors. Geneva, Switzerland: WHO, 2004.

[12] Kilbridge J, Baker TG, Paragia LA, Khoury SA, Shugaidef $\mathrm{SW}$, Jerwood D. Anaemia during pregnancy a risk factor for iron deficiency anaemia in infancy: a case-control study in Jordan. Int. J. Epid. 1999;28:461-8

[13] Goldenberg RL, Tamura T, Dubard M, Neggers Y, Coppers RL. Plasma ferritin and Pregnancy outcome. Amer J Obstet Gynecol 1996; 175: 1357-9.

[14] Rita M. Study of anaemia in pregnancy and its outcome in Nepal medical college. Nepal medical college Journal 2007 Dec;9(4):270-4.

[15] WHO/CDC. 2008. Worldwide prevalence of anaemia 19932005 : WHO global database on anaemia. De Benoist B, McLean E, Egli I, Cogswell $M$ eds. World Health Organization, Geneva. Available at http://whqlibdoc.who.int/publications/2008/9789241596657 _eng.pdf

[16] Nkuruma B, Nguah SB, Srprong N, Dekker D, Idriss A, Juergen M, Sarkodie YA. Haemoglobin estimation by Hemocue portable haemoglobin photometer in a resource poor setting. BMC Clinical Pathology, 2011; 11: 5.

[17] World Health Organization. Prevention and management of severe anaemia in pregnancy. WHO 1993. WHO/FHE/MSM/93-5.

[18] Dairo MD, Lawoyin TO. Socio-demographic determinants of anaemia in pregnancy at primary care level: A study in urban and rural Oyo state, Nigeria. Afr. J. Med. Med. Sci. 2004; 33: 213-217.

[19] Marti-Carvajal. Prevalence of anaemia during pregnancy: Results of Valencia- Venezuela. Arch. Latino Amer. De Nutricion Vol.52;1:2002

[20] Cyril D \& Hyacinth O. The prevalence of anaemia among pregnant women at booking in Enugu, Southern Nigeria. Medscape general Medicine. 2007; 9 (3):11

[21] Meda N, Mandesbrot L, Cartoux M, Dao B, Ouangre A,
Dabis F. Anaemia during pregnancy in Burkina Faso West Africa 1995-96: Prevalence and associated factors. Bull World Health Org. 1999;77:916-22

[22] Msolla MJ \& Kinabo JL. Prevalence of anaemia in pregnant women during the last trimester. Int. J. Food Sci Nutr.1997:48(4):265-70.

[23] Hoque M, Kader SB, Hoque E. Prevalence of anaemia in pregnancy in the Uthungulu health district of KwaZuluNatal, South Africa. SA Farm Pract. 2007; 49(6): 16.

[24] Critchley J, Bates I. Haemoglobin colour scale for anaemia in diagnosis where there is no laboratory: A systematic review. Int. J. Epidemiol. 2005: 34(6): 1425-1434.

[25] Singh K, Fong YF, Arulkumaran S. Anaemia in pregnancy a cross sectional study in Singapore. Eur. J. clinical Nutri. 1998;52:65-70.

[26] Bruno de Benoist, MaClean E, Egli I, Cogswell M, Editors World-wide prevalence of anaemia 1993-2005; WHO global database on Anaemia, 1-51.

[27] Bondevik GT, Lie RT, Ulstein M, Kvåle G. Maternal haematological status and risk of low birth weight and preterm delivery in Nepal. Acta Obstet Gynaecol Scand $2001 ; 80: 402-8$

[28] Yuan X, Hong Y, Shaonong D, Bianba Z, Xiaoyan Z, Duolao W. Hb levels and anaemia evaluation during pregnancy in the highlands of Tibet, a hospital-based study. BMC Public Health. 2009; 9:336.

[29] Anorlu RI, Oluwole AA, Audu OO. Socio-demographic factors in anaemia in pregnancy at booking in Lagos Nigeria. Journal of Obstetrics and Gynaecology. 2006; 268:773-776.

[30] Brabin BJ, Hakimi M, Pelletier D. An analysis of Anaemia and Pregnancy-Related Maternal Mortality. J. Nutri. 2001; 131:6045-6155.

[31] Komolafe JO, Kuti O, Oni O, Egbewale BE. Sociodemographic chararcteristics of anaemic gravidae booking: a preliminary study at Ilesha, Western Nigeria. Niger J. Med. $2005 ; 14(2): 151-154$.

[32] Oboro VO, Tabowei TO, Jemikalajah J. Prevalence and risk factors for anaemia in pregnancy in Southern Nigeria. Journal of Obstetrics and Gynaecology. 2002; 2296):610613.

[33] Mora JO, Nestel PS. Improving prenatal nutrition in developing countries: strategies, prospects and challenges. Am.J. clin. Nutri. 2000; 71:1353-1363.

[34] Rush D. Nutrition and Maternal Mortality in the Developing World. Am. J. Clin. Nutri. 2000; 72(1):212-240.

[35] Harrison KA. Anaemia in pregnancy. In: Lawson JB, Harrison KA, Bergstrom S, editors. Maternity Care in Developing Countries. $1^{\text {st }}$ ed. RCOG Press, London. 2001; 112-128.

[36] Akanmu AS, Abudu OO, Akinsete I. Influence of SocioEconomic status on haemoglobin and haematocrit levels during pregnancy in Lagos Nigeria. The Nigerian Postgrad. Med. J. 1998; 5(3): 131-135.

[37] Desalegn S. Prevalence of anaemia in pregnancy in Jima Town, Southern Ethiopia. Ethiop Med J. 1993:31(4):251-8 
[38] Kiwanuka GN, Isharaza WK, Mahmoud S. Iron status of pregnant women at first antenatal booking in Mbarara University Teaching Hospital. Trop Doct 1999;29:228-30.

[39] Jahan K \& Hossain M. Bangladesh National Nutrition survey, 1995-96 Dhaka: Institute of Nutrition and food science, University of Dhaka, 1998.

[40] Dreyfuss ML, Stoltzfus RJ, Shrestha JB et al. Hookworms, Malaria and Vitamin A Deficiency contribute to anemia and iron deficiency among pregnant women in the plains of Nepal. J Nutr 2000; 130: 2527-36.

[41] Atukorala TMS, de Silva LDR, Dechering WHJC, Dassenaeike TS de C, Perera RS. Evaluation of effectiveness of iron-folate supplementation and anthelminthic therapy against anaemia in pregnancy - A study in the plantation sector of Sri Lanka. American Journal of Clinical Nutrition 1994;60:286-92.

[42] Omoniyi YA \& Gregory S. Anaemia in pregnancy and race in the United States: Blacks at risk. Fam Med 2005;37(9):655-62.

[43] Looker AC, Dallman PR, Carroll MD, Gunter EW, Johnson CL. Prevalence of iron deficiency in the United States. JAMA 1997;277:973-76.

[44] Fujimori E, Oliveira IMV, Nuñez de Cassana LM, Szarfarc SC. Estado Nutricional del hierro de gestantes adolescentes, São Paulo, Brasil. Arch Latinoamer Nutr 1999;49:8-12 